\title{
PerCursos
}

\section{Utopia balneária no Rio Grande do Sul: o mar como refúgio na modernidade ${ }^{1}$}

\section{Resumo}

Nas últimas décadas do século XIX, o surgimento de balneários na costa atlântica do Rio Grande do Sul favoreceu a prática do veraneio, cujas finalidades terapêuticas eram prescritas pela medicina à época. Contudo, tal prática ganhou outros significados durante as primeiras décadas do século XX, quando a industrialização e a urbanização pautaram um novo "viver nas cidades". De modo concomitante, o planejamento de balneários marítimos significava a projeção de um espaço social livre dos problemas urbanos, representando, assim, uma utopia em pequena escala e por um curto período como o verão. Por meio da análise da bibliografia especializada, de fotografias, da revista impressa A Gaivota e de outras fontes sobre a história do litoral, este artigo pretende mostrar como as praias do Rio Grande do Sul constituíram um refúgio na modernidade, quando, entre as décadas de 1920 e 1950, a vida junto ao mar representava para o imaginário social uma utopia balneária, por seu ideal de uma vida melhor.

Palavras-chave: Mar. Litoral gaúcho. Utopia. Modernidade. Balneários marítimos.
Joana Carolina Schossler

Doutora em História pela

Universidade Estadual de

Campinas - UNICAMP.

Professora substituta no Instituto

Federal de Educação, Ciência e

Tecnologia de São Paulo - IFSP, campus Capivari.

Brasil

mergulhandonolitoral@gmail.com

\section{Para citar este artigo:}

SCHOSSLER, Joana Carolina. Utopia balneária no Rio Grande do Sul: o mar como refúgio na modernidade.

PerCursos, Florianópolis, v. 22, n.48, p. 430 - 455, jan./abr. 2021.

\section{DOI: $10.5965 / 1984724622482021430$}

http://dx.doi.org/10.5965/1984724622482021430

\footnotetext{
${ }^{1}$ Este artigo é uma adaptação do resultado da tese de doutorado intitulada Utopias marítimas no Atlântico Sul: imaginário e tipologias no litoral do Uruguai e do Rio Grande do Sul (1860-1950). Esta pesquisa foi financiada pela FAPESP.
} 


\title{
Utopia bathing resort in Rio Grande do Sul : the sea as refuge of modernity
}

\begin{abstract}
In the 19th century's last decades, the emergence of seaside resorts on the Atlantic coast of Rio Grande do Sul favored the summer vacation practice, whose therapeutic purposes were prescribed by medicine at the time. However, this practice acquired other meanings during the 2oth century's first decades, when industrialization and urbanization led to a new "living in the cities". At the same time, the planning of seaside resorts meant the projection of a social space free of urban problems, thus representing a utopia on a small scale and for a short period like the summer. Through the analysis of specialized bibliography, photographs, the printed magazine A Gaivota, and other sources on the coastal history, this study aims to show how the beaches of Rio Grande do Sul were a refuge in modernity, when, between the 1920 s and 1950s, life by the sea represented for the social imaginary a seaside utopia, for its ideal of a better life.
\end{abstract}

Keywords: Sea. Gaucho coast. Utopia. Modernity. Sea resorts. 


\section{Introdução}

Há cerca de 500 anos, ao efetuar uma crítica à sociedade de seu tempo, Thomas Morus concebeu o conceito de utopia, dando matriz ao gênero literário que se refere a uma sociedade ideal. Ao longo da história, o termo foi explorado de distintas maneiras, sendo que essas variações e análises plurais o tornaram abrangente e polissêmico.

Nas utopias, a igualdade e a felicidade suprema são os princípios do sonho de uma sociedade perfeita, tal qual inferidas nos textos clássicos de Platão, Morus, Campanella, Owen, Fourier, Bloch ou mesmo em utopistas menos renomados, que vêm ganhando evidência em traduções e pesquisas realizadas nos centros de estudos especializados sobre o tema².

Em 1516, quando a obra-prima de Morus foi publicada, novos territórios, a exemplo da América, estavam sendo "descobertos" pelos europeus. Eles, por sua vez, abarcavam o imaginário de um mundo melhor, puro e inexplorado, próprio à fantasia dos eutopistas, que, entre o sonho e o pesadelo, estavam prontos para descobrir esses outros lugares, desertos e talvez inexistentes (SARGENT, 2000).

O texto a seguir discorre sobre um território simbólico que se localiza no litoral ao sul do oceano Atlântico; trata-se do oceano-mar, essa imensidão líquida que existe diante do nosso estado de contemplação. Mas, não é o mar enquanto seu aspecto físico, e sim sobre a forma como o sistema econômico e político criou um espaço entre a terra e o mar, conferindo a ele valores sociais e culturais que denominamos como praia.

Se o pressuposto de utopia é um "lugar ou um país imaginário", nesse caso, esse lugar está em um mundo conhecido e palpável (FIRPO, 2005), que se localiza geograficamente no litoral norte do Rio Grande do Sul. Nesse espaço distante das mazelas das cidades, do ar viciado, da indústria, dos ruídos dos automóveis e da vida moderna da década de 1930, foi sonhado e inventado um mundo ideal à beira-mar.

\footnotetext{
${ }^{2}$ Ver a coleção Mundus Alter, que vem sendo traduzida e publicada pela Editora Unicamp: CHERSO, 2011; FOIGNY, 2011.
} 
Ao se entender o veraneio como uma possibilidade de vida melhor junto ao mar, a definição pensada por Norbert Elias (2014, p. 33) sobre o conceito de Utopia é aquela que mais se aproxima da interpretação da praia como um lugar melhor para se viver, pois o autor acredita que "utopia é a representação imaginária de uma sociedade, que é de certo modo diferente da sociedade atual em que vivem aqueles que nos propõem esta representação".

Elias (2014, p. 36) também concorda com o texto literário de Morus, ao supor que “todas as utopias, sejam elas temidas ou desejáveis, se remetem aos conflitos da sociedade de origem, pois elas podem ou não resolver esses conflitos". O sociólogo ainda avança ao propor que a utilização do conceito de utopia possa servir como uma hipótese de trabalho para analisar as representações coletivas, e sugere que os problemas sociais não sejam analisados apenas sob a perspectiva do texto literário da sociedade imaginária, já que, para ele, a utopia é um exemplo de objeto de pesquisa que transcende olhares acadêmicos interdisciplinares (ELIAS, 2014).

Já o sociólogo francês Alain Touraine entende que utopia é um discurso para uma sociedade criadora dela mesma, e que a história da utopia começa quando a sociedade abandona a imagem do paraíso. Nesse sentido, o sociólogo salienta que:

[...] "utopia não está voltada nem em direção ao passado, nem ao futuro, ela é uma vontade do presente, ela constrói uma sociedade que é sua própria razão de ser”. [...]. A utopia, tal qual Thomas Morus construiu, não é a criação de uma sociedade imaginária contra a sociedade real, mas corresponde à consciência que uma sociedade tem de constituir sua própria razão de ser, que o bem é o bem comum, que o indivíduo deve se submeter inteiramente à sociedade para alcançar a felicidade e a realização dele mesmo. Essa ideia carrega a esperança da modernidade nascente. (TOURAINE, 2000, p. 30-31, grifo nosso)

Assim, ao analisar o desejo pelas praias balneárias, entende-se que o litoral serviu de válvula de escape para as sociedades urbanas, que se encontravam em franco processo de urbanização e industrialização no início do século XX. Nesse sentido, veremos como o pitoresco da paisagem, a natureza bucólica, o território inabitado e a 
prática cultural e medicinal dos banhos de mar contribuíram para a construção do imaginário de uma vida melhor junto ao mar, onde a sociedade criou novos hábitos de vida, novas relações individuais e sociais, novas comunidades, novas formas de habitar e transformar o espaço marítimo em um espaço de sociabilidade.

\section{O mar como refúgio na modernidade}

No início do século XX, um território costeiro no Rio Grande do Sul, cercado por campos arenosos, lagos, vegetação arbórea e cactos foi imaginado por engenheiros urbanistas como uma cidade balneária. O sonho para aquela paisagem pitoresca parecia ser para os veranistas gaúchos uma ilusão, uma visão do futuro, uma utopia, pois não muito longe daquelas terras, os banhistas transitavam entre os rigores dos banhos de mar terapêuticos e o culto ao sol, descobrindo as formas de ser moderno. Assim, em harmonia com a descoberta e os prazeres da vida ao ar livre, os corpos físicos, bronzeados à beira do Atlântico, passaram a ser estampados nos jornais e nas revistas ilustradas do Rio Grande do Sul, nas quais apareciam flagrados em momentos de descanso, alegria, prazer e diversão.

A costa marítima foi transformada pelo aumento do desejo de se estar mais perto do mar. Sua apreciação e ocupação tornaram o litoral um território acolhedor e habitável para os veranistas, em que o período de vida junto ao mar pode ser lido como um tempo fora do ritmo frenético da vida urbana, um refúgio da modernidade, um lugar melhor para se viver, mesmo que por um curto tempo, como o verão.

O mar como refúgio na modernidade já foi objeto de estudo desde o precursor trabalho do historiador francês Alain Corbin (1988), o qual mostrou como a descoberta da praia estava associada aos males e anseios vividos pelas sociedades urbano-industriais. Assim, se na modernidade as utopias foram pensadas como uma forma de melhorar os problemas vividos pelas sociedades contemporâneas, a praia passou a representar um lugar de solução para tratar os problemas de nível individual e social da sociedade burguesa, pois, em seu espaço, comunidades de veranistas se organizaram a partir da 
prática do banho de mar, dando forma e função a um território, a partir do qual as metáforas invadiram os discursos para justificar a sua ocupação.

Nesse sentido, a busca da praia como uma vida melhor em relação à sociedade de origem se define, conforme o conceito estipulado por Norbert Elias (2014, p. 38), como “utopia de representação imaginária”, porque seria uma solução possível para verdadeiros problemas sociais do seu tempo. A partir dessa acepção do conceito de utopia, podemos perceber que o desejo pela beira-mar possibilitou que comunidades imaginárias se organizassem no litoral, com o ideal de uma vida melhor junto ao mar.

Para entender esse ideal, é preciso mergulhar na história dos banhos de mar do Rio Grande do Sul do final do século XIX, e passar pelo longo caminho para se chegar até as praias, no qual o encontro com a paisagem pitoresca e os preceitos terapêuticos dos banhos de mar fundamentaram a ideia de paraíso localizado nos mares. É nesse lugar que serão interpretadas as representações sobre o modo de uso desse território que, ao passar pelos discursos da saúde e da higiene, se encontrará com a sociabilidade, a tipologia arquitetônica e o imaginário da vida melhor ao ar livre.

\section{Utopia, representação e imaginário nas praias do Rio Grande do Sul}

No final do século XIX, as estações balneárias do litoral norte do Rio Grande do Sul se desenvolveram devido à presença de imigrantes europeus que, ao encontrarem um mar de águas geladas muito semelhante ao de seu lugar de origem, incorporaram a prática dos banhos de mar ao novo ambiente de vida. Esse hábito garantiu que as praias se desenvolvessem em torno dos aspectos terapêuticos, considerando que a iniciativa e o investimento do capital econômico de imigrantes europeus foram imprescindíveis para o desenvolvimento de hotéis e serviços para atender turistas e banhistas (SCHOSSLER, 2013).

No início do século XX, as viagens até as praias eram realizadas com carroças de bois e levavam cerca de oito dias de deslocamento (Imagem 1). Saindo de Porto Alegre até as praias de Cidreira, Capão da Canoa ou Tramandaí, essa viagem morosa significava a 
maior dificuldade para chegar ao litoral, demarcando assim uma distância física e temporal desse encontro com o mar.

Imagem 1 - Carroças de bois e banhistas à beira-mar de Tramandaí. Ao fundo, à esquerda, estão localizados os biombos em palha para a troca de roupas. Sem data.

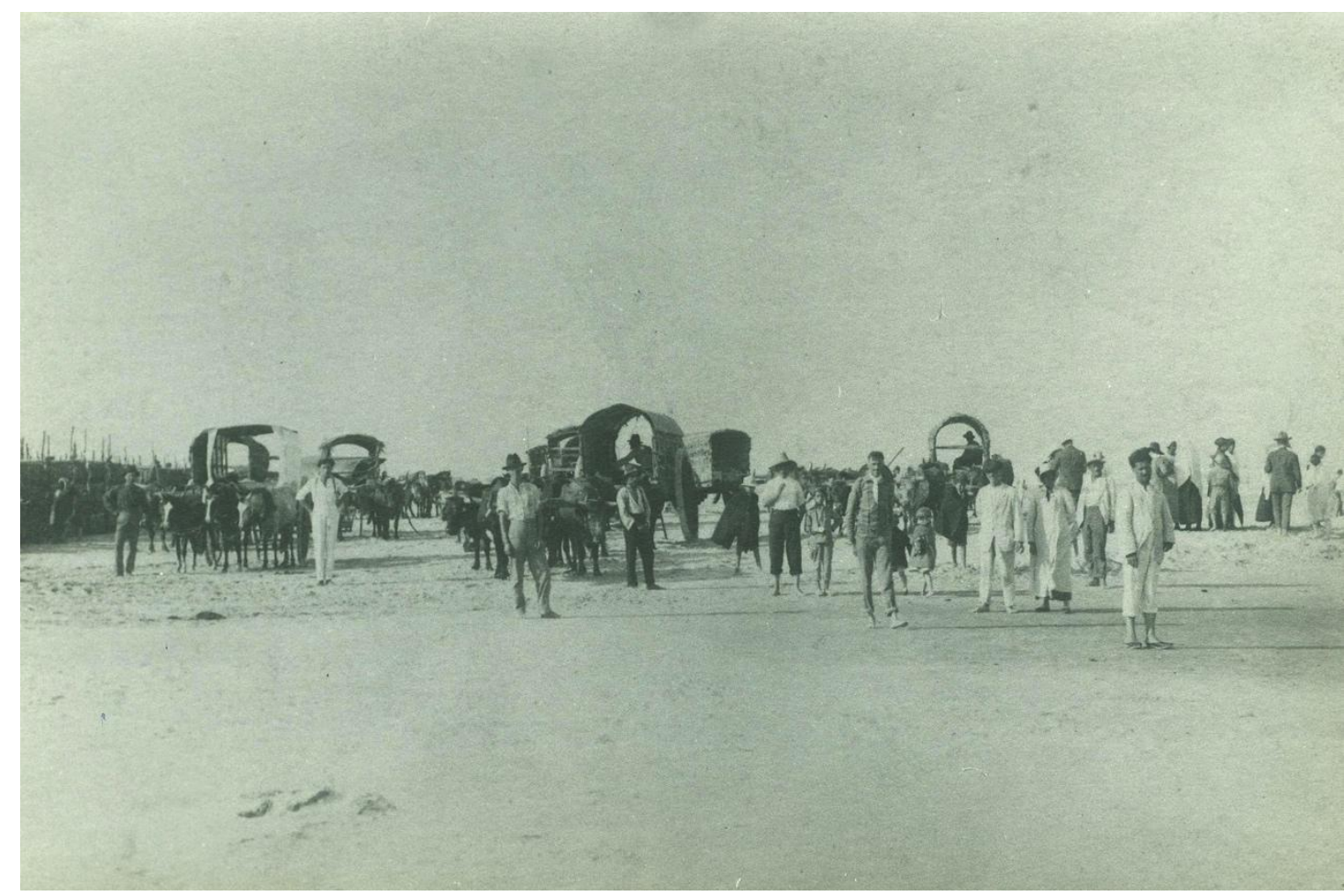

Fonte: Acervo Museu Visconde de São Leopoldo, Caixa 80- Praias, Imagem: 80.66.

A dificuldade de acesso dos veranistas ao litoral contribuiu para a formação da imagem da praia como um lugar onírico, pois ele se situava em um território distante dos males da vida urbana, sendo, portanto, um lugar oposto ao lugar habitado, incitando a fantasia e o desejo por esse território ainda "vazio", onde era possível restituir a saúde, resgatar os sonhos de vida e restabelecer os laços afetivos com a família.

O litoral do Rio Grande do Sul é dividido espacialmente entre norte e sul, e ainda que as estações balneárias em cada uma dessas partes do território marítimo tenham se constituído de forma quase simultânea, elas guardam algumas diferenças e particularidades em relação à sua organização e estrutura. Nesse sentido, se os 
balneários no litoral norte se desenvolveram com o investimento econômico de comerciantes ou de famílias burguesas, já na faixa litorânea sul do Rio Grande do Sul, um balneário, de modelo europeu, foi planejado por um grupo de empresários que visava a atender a elite agropecuária do estado. O empreendimento foi iniciado em 1885 quando, após a inauguração da linha ferroviária que conectava a cidade de Bagé a Rio Grande³, a companhia ferroviária percebeu o interesse de viajantes pelas praias de Rio Grande, decidindo construir uma linha que ligava o centro urbano à beira-mar (ENKE, 2005).

Para a realização do empreendimento, a Companhia Carris Urbanos tinha como referência os reputados balneários do Uruguai, Ramirez e Pocitos, além dos prestigiados balneários europeus, vislumbrados devido à presença de imigrantes e por meio de revistas que circulavam na cidade (ENKE, 2005). Em 1890, o balneário foi inaugurado com o nome do diretor da empresa ferroviária Carris, Antônio Candido Sequeira, tornando o balneário Villa Sequeira um empreendimento de destaque e prestígio para a sociedade rio-grandina e para seus vizinhos uruguaios, conforme revela a seguinte observação encontrada em um livro do acervo do Real Gabinete Português de Leitura, da Biblioteca Nacional, no qual Manoel d'Azevedo Silva comenta o esforço em domar o deslocamento das dunas para tornar o local balneável e de estrutura semelhante ao que o país vizinho apresentava.

A partir da cidade do Rio Grande até o Maldonado (Uruguai), encontra-se uma extensa costa, que pode prestar-se aos banhos de mar. Bastante desabrigada e exposta aos fortes ventos, tem-se formado vastas dunas em todo o seu percurso, o que difficulta d'alguma sorte a pratica hydrotherapica. A municipalidade já tentou uma vez a plantação de pinheiros afim de impedir o deslocamento das areias a exemplo do que se fez em Arcachon - França, porém a falta de constância dos poderes municipaes annulou a boa vontade dos que só desejavam o bem e o progresso de seu torrão natal.

Formando um isthmo na entrada da barra do Rio Grande, acha-se situada a Mangueira, esplendido e pittoresco arrabalde, distante 6 milhas do Rio Grande, ponto escolhido pela aristocracia d'este Estado e de Montevidéo para villegiatura, cuja estação vai de Novembro a Março. Os confortos

\footnotetext{
3 Rio Grande é desde 1882 uma cidade portuária, sendo um importante polo econômico do Estado do Rio Grande do Sul na atualidade.
} 
que offerece o grande Hotel Internacional, as innumeras barracas estendidas sobre a costa, o excellente clima, a alegria e a vida que reina na villa, tornam a Mangueira um local predilecto para a hydrotherapia maritima.

Um pouco mais além acha-se a praia de Mostarda, muito desabrigada, tendo mar muito batido e não convindo para a pratica hydrotherapica. (SILVA, 1893, p. 112-113)

O balneário na praia do Cassino foi constituído de acordo com o ideal e a tipologia dos balneários europeus, formado por um hotel à beira-mar, casinhas de banho e, sobretudo, trilhos de trem, os quais favoreceram o acesso e o desenvolvimento da estação de vilegiatura marítima. O hotel construído à beira-mar, possuía cerca de 700 metros e era composto por varandas cobertas, 136 quartos, 8 lojas, salão de jantar, banheiros, waterclosets e cassino (FERREIRA, 2005).

A tipologia em estilo inglês, em madeira e com cabines de banhos individuais e separadas por gênero masculino e feminino, e que iam até a água ou próximo, indica que o balneário foi estruturado dessa maneira devido ao capital econômico empreendido pelos promotores da companhia ferroviária de origem inglesa, mas também pela presença de imigrantes da mesma nacionalidade; pois conforme demonstra o censo de 1888, de uma população total de 20.227 habitantes, 21,7\% eram estrangeiros, sendo 191 deles, franceses e ingleses (FERREIRA, 2012).

Essas evidências também se comprovam pelas sociabilidades praticadas à beiramar, sendo que as corridas a cavalo, o cricket, os passeios em carruagens e os jogos de bola de borracha eram os lazeres mais usuais "próximos da varanda e dos camarotes" da estação balneária (FERREIRA, 2012, p. 78).

Ainda que a referência ao modelo dos balneários europeus e uruguaio, que possuíam uma tipologia de hotel, parque, jardins, restaurantes e píer, tenha sido bastante fundamentada pelo capital cultural e financeiro de investidores italianos, franceses e ingleses, formando então diferentes estruturas para receber banhistas no início do século XX (SCHOSSLER; TOULIER, 2020), percebe-se que esses fatores inspiraram a construção do Hotel Cassino, em Rio Grande, mesmo que a edificação do estabelecimento tenha se 
expressado de maneira simples, pois foi construída em madeira e com pouco requinte arquitetônico. Ainda assim, o hotel congregava os principais espaços de sociabilidades indispensáveis para os prazeres em torno do mar e alguns desses espaços, como o restaurante, a "sala de casa de campo" e o salão de jogos e festas (FERREIRA, 2012, p. 105-106), faziam do hotel um atrativo de distinção no início do século XX.

Conforme demonstram as pesquisas de Pinheiro (1999), Enke (2005) e Ferreira (2012), a edificação de Villa Sequeira e sua estrutura à beira-mar possibilitaram que um traçado urbano se expressasse na estação balneária, passando a atrair banhistas, que lá edificaram as primeiras casas de veraneio, nas primeiras décadas do século XX.

Apesar do seu ar aristocrático e da pretensão em se fazer ser, o acesso dificultoso e moroso até a cidade de Rio Grande parece ter sido um empecilho aos banhistas metropolitanos, que acabaram elegendo os balneários do litoral norte como lugar de preferência para o veraneio. Essa proximidade com a cidade de Porto Alegre também permitiu que as relações urbanas fossem estendidas ao ambiente marítimo, onde os banhistas podiam partilhar seus interesses em comum. Em vista disso, é importante considerar que, além das grandes distâncias que limitavam o acesso ao litoral sul, possivelmente a comunidade porto-alegrense não se identificava com a elite agropecuária do Estado, elegendo então o litoral norte para a prática do veraneio.

Conforme destaca Bernard Toulier (2004), os lugares de vilegiatura se organizam sob os preceitos medicinais e climáticos, mas também em função de sua acessibilidade em relação aos grandes centros urbanos e metropolitanos, que tornaram os balneários uma zona de cruzamento, um espaço dinâmico de trocas, de circulação e de comunicação entre suas relações sociais, culturais e territoriais.

Acerca dessas ideias, ainda é possível considerar que as polaridades que se estabeleceram em relação ao litoral norte e sul não se deram particularmente devido à arquitetura ou à distinção social dos banhistas que frequentavam um balneário ou outro — até porque ir à praia com finalidade terapêutica ou de descanso, entre o final do século XIX e o início do XX, era um privilégio de poucos, o que representava a realidade social de ambos os balneários frequentados pelas elites do estado. Logo, o que parece demarcar a 
diferença entre o Villa Sequeira e os balneários do Litoral Norte é o desenvolvimento de comunidades balneárias, as quais foram permeadas pelas características culturais de seu ambiente de origem e que, assim, passam a determinar o dinamismo de cada balneário (ROUILLIARD, 1984).

Se o universo urbano se transpõe para a beira-mar, as praias se tornam um lugar onde é possível reafirmar os laços e os interesses sociais, formando uma comunidade de verão. Conforme destaca o antropólogo Jean-Didier Urbain (2007, p. 234-244), o sentido de comungar um mesmo espaço se constitui no ritual de um tempo que se repete e que é moldado por outra realidade, avessa ao mundo de origem, para o qual a praia constitui "um espaço fantástico e paradoxal”, um mundo idílico onde se formam modos e costumes balneários que darão ritmo e sentido a esse tempo que se repete a cada verão.

Guiados pela ideia de uma vida melhor, essas comunidades que se formam durante o verão estão circunscritas aos prazeres que se encontram no cotidiano em torno do mar e aos discursos que justificam essa prática. Conforme indica Nicolas Laurence (2008), a emergência dessa comunidade determina uma experiência marcante sobre a vontade de retorno a um equilíbrio perdido, a um ritmo de vida calmo, a um modo de relações livres das determinações sociais.

No Rio Grande do Sul, com o apogeu do comércio e da indústria nas primeiras décadas do século XX, o nervosismo da vida urbana e o cotidiano eletrizante da cidade convidava seus habitantes a saírem da cidade, tornando os refúgios cada vez mais necessários para uma vida mais calma, mas também uma forma de distinção social em uma época em que não havia férias remuneradas (SCHOSSLER, 2013).

Em vista disso, a vida que se estabelece durante o ritual de veraneio pode ser interpretada por meio do conceito de comunidades imaginadas, de Benedict Anderson 4 (2008, p. 32), pois a praia não é apenas uma realidade contrária ao mundo de origem, ela é um espaço comum, onde os "indivíduos agrupados se reconhecem como semelhantes" e se sentem partilhando a mesma experiência de ir ao mar durante o verão.

\footnotetext{
4 O livro, lançado no Brasil em 2008 pela Companhia das Letras, trata de um estudo sobre os estados nacionais e a ascensão do sentimento nacional.
} 
Nesse sentido, esse deslocamento comum até o mar permite entender outros significados constituídos no ritual do veraneio, como a relação com o espaço e as experiências que são vividas nele (PISTORELLO, 2011). Esse significado cultural que se atribui ao veraneio ultrapassa, inclusive, as fronteiras do espaço marítimo, pois ele também é imaginado por aqueles que nunca veranearam ou estiveram na praia.

Portanto, mais do que inventada pelos grupos que reproduziram nesse espaço as práticas culturais dos banhos de mar e suas sociabilidades em torno dele, a praia é também imaginada a partir de seus elementos, constituídos pelas narrativas sobre a natureza, pelas pessoas que frequentam o local, pelas sensações e pelas experiências, que possibilitam mesmo para aqueles que nunca vivenciaram a experiência dos banhos de mar ter em mente a ideia de comungar dessa prática presente no imaginário social (ANDERSON, 2008). Essa projeção também é constituída pelas fotografias que contribuíram na formação do desejo e na elaboração de um imaginário comum, no qual a praia representa um sentido de igualdade, felicidade e harmonia (Imagem 2).

Em vista disso, é possível considerar que a criação do periódico A Gaivota, revista das praias balneárias do Rio Grande do Sul, foi um importante instrumento de fortalecimento para a comunidade imaginária. De acordo com o grupo de veranistas responsável pelo surgimento da revista em 1929, o objetivo era de "reproduzir em suas páginas a vida praiana, em todas as suas minúcias e detalhes, focalizando os fatos desenrolados, nesses dias maravilhosos que passamos na orla do mar" (JORNADA..., 1940). 
Imagem 2 - Banhistas na praia, sem data e local, estimativa anos 1920

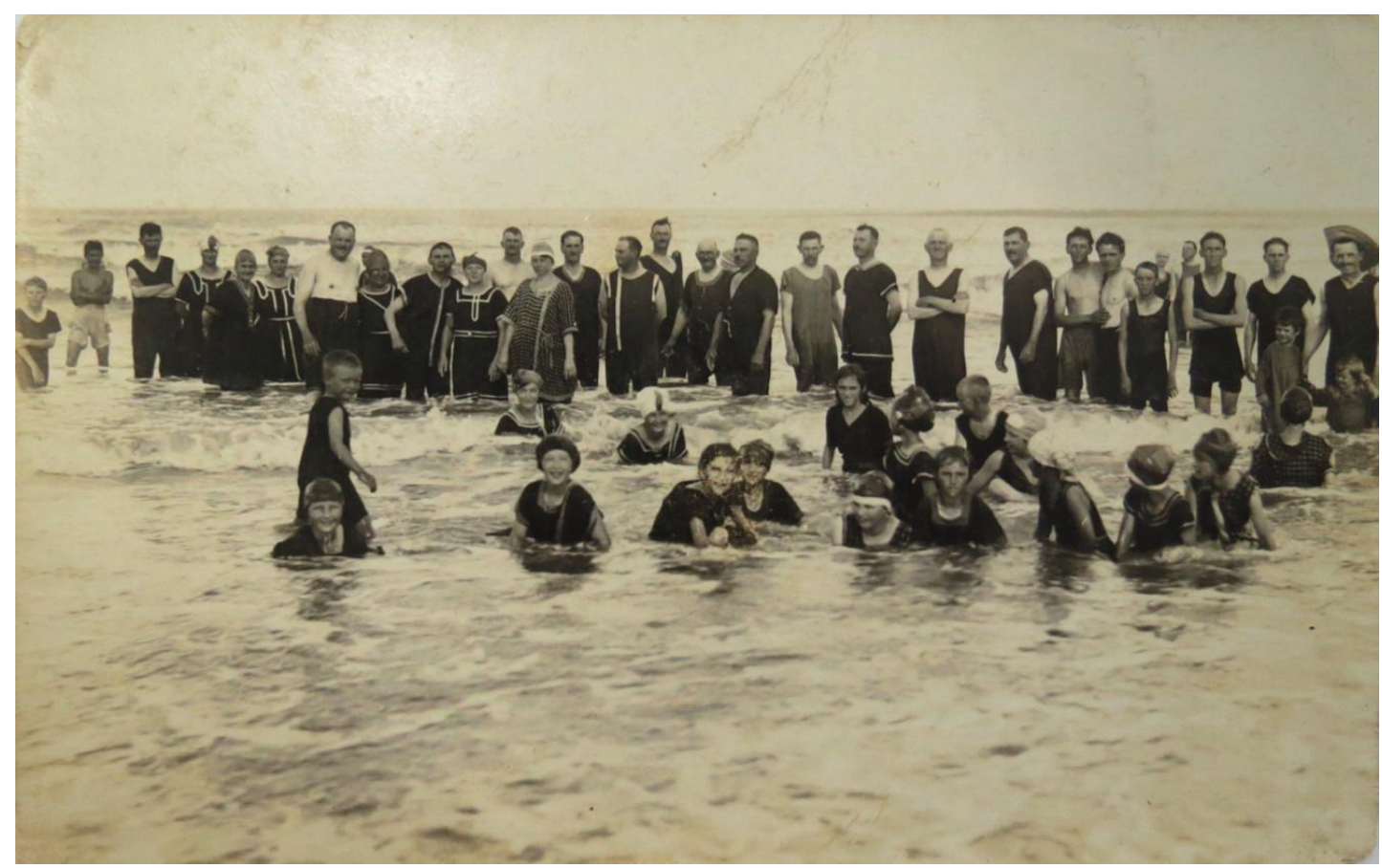

Acervo: Museu Visconde de São Leopoldo, São Leopoldo/RS, fotos avulsas.

A revista impressa circulou nas comunidades de verão, sendo que sua linguagem escrita e fotográfica fortaleceu o sentido de unidade e pertencimento aos frequentadores desses balneários, pois seus nomes e imagens eram divulgados a cada ano, garantindo prestígio pessoal, bem como ao balneário (DE PORTO ..., 1929, p. 39). Entre os anos de 1929 a 1965, com publicação anual e com alguns períodos de interrupção, suas páginas mostram o desenvolvimento das praias balneárias e da prática social do veraneio, e enfatizam como essas comunidades contribuíram para a melhoria e a construção do espaço marítimo para acolher o sonho de uma vida melhor (Imagem 3 e 4). 
Imagem 3 - Capa do primeiro número da Revista A Gaivota de 1929

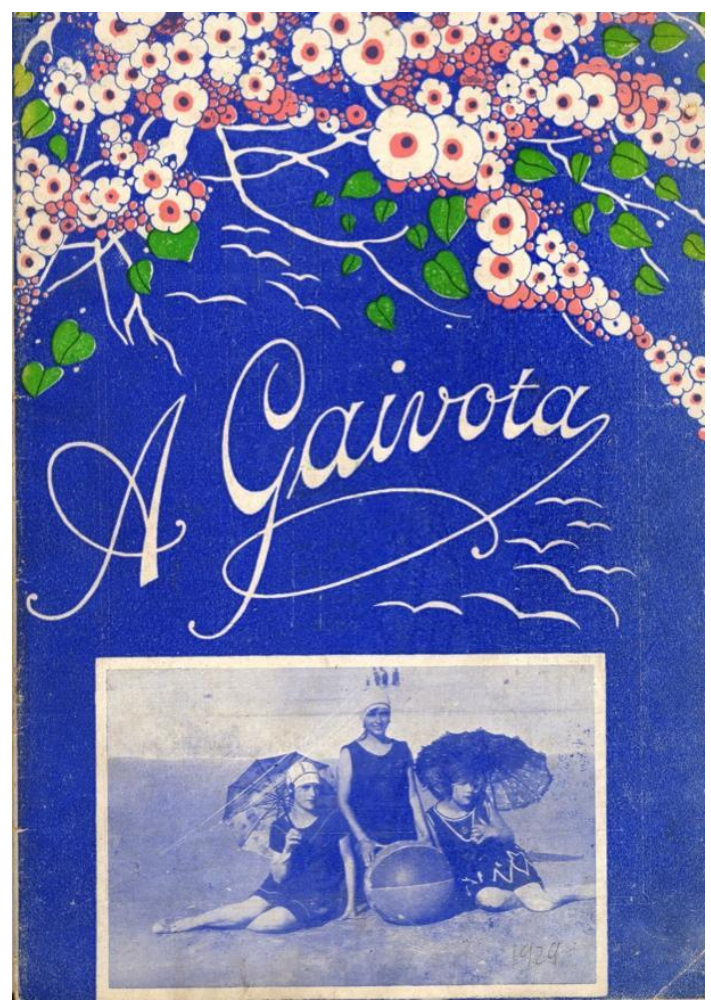

Acervo: IHGRS.
Imagem 4 - Página interna da Revista A Gaivota, de 1931, ressaltando aspectos da natureza pitoresca da praia de Torres

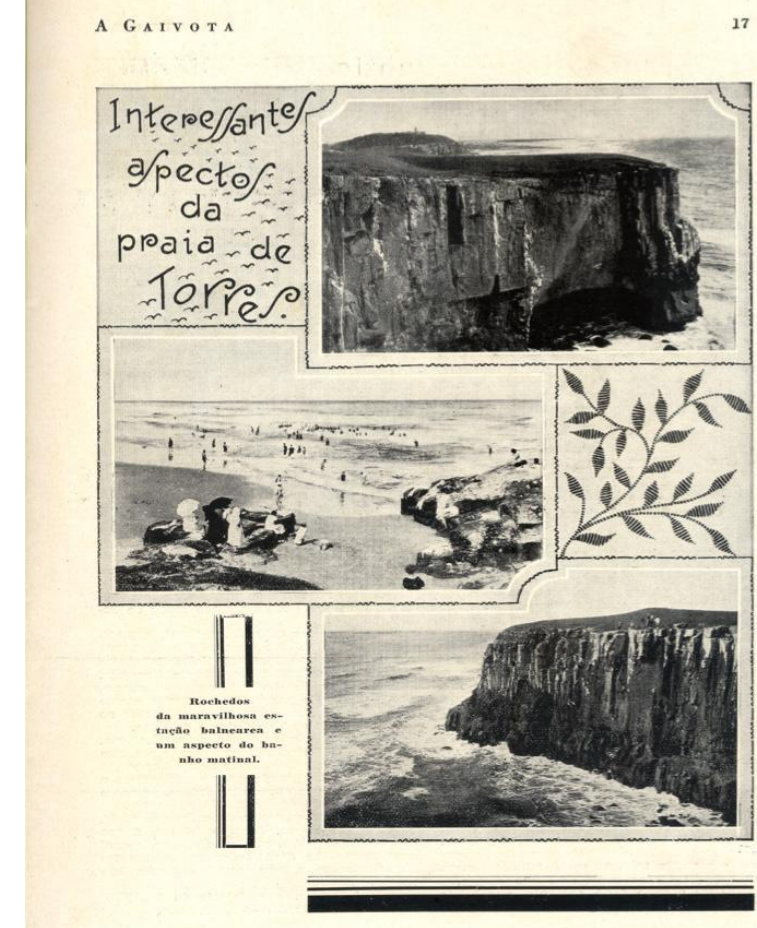

Acervo: IHGRS.

No início dos anos 1920, as principais estações balneárias, nas praias de Cidreira, Tramandaí, Capão da Canoa e Torres, localizadas no litoral norte, já possuíam significativa reputação social e contavam com cerca de 14 hotéis $^{5}$ construídos em madeira, com uma arquitetura modesta e de pouco conforto. Apesar da falta de requinte, essa tipologia comum aos estabelecimentos balneários congregava o núcleo familiar que, em contato com a natureza e com outros indivíduos, dava início aos primeiros códigos de comportamento da vida em sociedade.

\footnotetext{
${ }^{5}$ A estatística foi levantada nos anúncios do Jornal Correio do Povo e da Revista A Gaivota. Pode ser que tenham existido outros estabelecimentos menos conhecidos, mas entre os mais populares estão: Hotel da Saúde (Tramandaí), Grande Hotel Atlântico (Cidreira), Hotel Primavera (Capão da Canoa), Hotel Familiar (Cidreira), Hotel Sperb (Cidreira), Balneário Menegatti (Cidreira), Novo Hotel (Cidreira), Hotel Strasburguer (Tramandaí), Parque Balnear (Tramandaí), Hotel Esperança (Cidreira), Hotel Rio Grandense (Capão da Canoa), Hotel Bassani (Capão da Canoa), Balneário Hotel Torres (Torres), Hotel Picoral (Torres).
} 
Os hotéis foram os principais responsáveis na gestão do tempo dos banhistas durante a estada à beira-mar, delimitando as regras sobre o tempo dos banhos, das refeições e da diversão. Além de suprir as primeiras necessidades pessoais dos banhistas, os empreendedores hoteleiros também foram os responsáveis pelo surgimento e desenvolvimento dos balneários, garantindo o fornecimento de água potável, eletricidade, melhoria de estradas e transporte (SCHOSSLER, 2013).

Se, inicialmente, as motivações para ir à praia passaram pelo benefício terapêutico dos banhos de mar, foi ao alcançar o hedonismo que a praia passou então a ser associada ao tempo de descanso e prazer. Ainda que o direito às férias pagas não fosse uma conquista de todos na década de 1920, o afluxo de banhistas nas praias no início da década de 1930 era a cada ano maior, podendo ser notado por meio do crescimento de empresas de transportes para o deslocamento até as praias, mas também nas fotorreportagens divulgadas nas Revistas do Globo (SCHOSSLER, 2013), que evidenciam o início da popularização da beira-mar e demarcam um tempo de mudança física, social e cultural, que passou a contar com investimentos públicos e privados a partir da década de 1930.

A conquista da praia como lugar hedonista modificou a relação das pessoas com o local, despertando nos banhistas outros interesses, como o desejo de habitar o litoral durante os meses de verão. Assim, é possível perceber que essa vontade é intrínseca aos laços que se estabelecem com o lugar de veraneio, no qual, a revista A Gaivota (NONOHAY, 1929, p. 22) revela, em um artigo sobre “As Férias", que os elos são estabelecidos "primeiro pelo convite de amigos e depois pelo hábito, pois a pessoa se acostuma com o lugar e depois segue indo lá".

O fortalecimento da comunidade de verão também ocorre a partir das relações vividas nos hotéis e nas atividades congregadas em torno dele, como jantares, festas e jogos. Essas sociabilidades, circunscritas a um espaço delimitado, também englobam os espaços públicos, como os banhos de mar e as festas religiosas de Nossa Senhora dos Navegantes, em Tramandaí, ou Nossa Senhora da Saúde, em Cidreira. 
Esse sentido religioso foi destacado por Anderson (2008) na constituição de comunidades imaginadas e pode ser atribuído ao balneário marítimo por meio da construção da igreja, pois ela se tornou um símbolo comum da união entre veranistas de diferentes regiões do Rio Grande do Sul, os quais, ao se tornarem devotos do padroeiro daquela comunidade, possivelmente se sentiam aceitos, criando um vínculo espiritual com a comunidade. Em seu primeiro número, a revista A Gaivota (IGREJINHA..., 1929, p.28) mostra uma imagem que recordava a inauguração da Igreja Nossa Senhora da Saúde na praia de Cidreira em 1924, criando, assim, um suporte de memória e para a construção da identidade daqueles que frequentavam aquela praia. No mesmo número, também são ressaltados os detalhes da festa que aconteceria naquele ano de 1929, fato que mostra o envolvimento da comunidade de banhistas, já que, na organização da festa, também encontravam uma forma de se destacar socialmente.

Cidreira, neste momento, engalana-se para seu culto à milagrosa santa e, desde hontem, aumenta extraordinariamente o movimento em nossa praia com a vinda de caravanas de forasteiros que, de Quintão, Tramandahy, Capão da Canoa, Torres e Porto Alegre, ocorrem a participar das comemorações que serão revestidas de grande brilho, graças aos esforços dispendidos [...] pelo festeiro Dr. Oswaldo Vergara e a juíza Exma. Sra. D. Maria da Gloria Rasgado.

A missa solemne será celebrada às 10 horas, sendo que, por essa ocasião, será cantada por uma nossa patrícia a "Ave Maria".

Do interior virá um reverendo padre, que officiará na grande festividade religiosa.

O orgão será ocupado por um digno maestro e o côro, que se acha afinadíssimo, será composto de senhoras e senhoritas da nossa elite.

Terminada a festa realizar-se-á o sorteio para festeiro no anno de 1930. (A GAIVOTA, 1929, p. 36, grifo nosso)

Em vista do crescente interesse da população pelas praias de mar, em 1930, o Governo do Estado do Rio Grande do Sul realizou uma inspeção nas praias balneárias, enviando o então diretor do Departamento de Higiene, Fernando de Freitas e Castro, para inaugurar a Delegacia de Saúde na praia de Torres e apontar as falhas que precisavam ser corrigidas em todos os balneários (CONDIÇÕES..., 1930, p. 32). Ao conceder entrevista ao 
jornal Diário de Notícias, reproduzida na revista das praias de 1930, o diretor Freitas e Castro justificava a ação como forma preventiva de cuidar dos balneários, que "eram muito procurados para repouso às fadigas do ano, necessitando perfeitas condições para que as epidemias não se propagassem" (A GAIVOTA, 1930, p. 32). O diretor ainda informa que a inspeção fazia parte do projeto do código sanitário que estava sendo organizado pelo Governo Estadual, e que o "zelo pelos pontos de veraneio" se inspirava nas políticas sanitárias da América do Norte (CONDIÇÕES..., 1930, p. 32 ).

A avaliação positiva sobre as praias gaúchas confirmava os ideais de higiene de vida de acordo com os princípios da modernidade, pois o diretor afirmava que as condições das praias eram "muito boas", mas que, por terem sido "criadas sem orientação e feitas aos pedacinhos, estão cheias de defeitos, alguns dos quais precisam ser corrigidos, para evitar graves consequências futuras" (CONDIÇÕES..., 1930, p. 32). Com essa crítica, o diretor apontava as providências que deveriam ser tomadas em relação aos balneários, criando tensões em relação ao investimento privado dos hoteleiros e justificando a intervenção do poder público por razões sanitárias, como demonstra a seguinte passagem:

Na minha visita, dei ordens para retirar das proximidades dos hotéis os chiqueiros, galinheiros, cocheiras, estábulos, etc. Que são focos de produção de moscas, e fiz com que o lixo, principalmente o proveniente das cozinhas, fosse removido em latas fechadas, para lugares distantes e aí enterrado.

Com o auxílio da Delegacia de Saúde de Torres e das autoridades policiais das outras praias, ficou sendo feita a fiscalização do asseio dos terrenos situados, principalmente, nas imediações dos hotéis e também dos gêneros alimentícios, das frutas, etc.

Os proprietários dos hotéis já foram notificados das modificações que deverão introduzir em seus abastecimentos, logo que termine a estação de veraneio. Na do ano vindouro, a Diretoria de Higiene pretende mandar para cada praia um fiscal, encarregado de zelar pelo asseio, fiscalizar a qualidade dos gêneros alimentícios, a matança, o comércio de frutas, etc. (A GAIVOTA, 1930, p. 32). 
Apesar do diretor de Higiene registrar ser a prioridade do poder público resolver os problemas de saneamento e da água potável nas praias, nos anos consecutivos essas necessidades continuaram sendo supridas pela iniciativa dos empreendedores hoteleiros, que desde o princípio proveram as estações balneárias com esses serviços básicos, marcando, assim, a fase em que os balneários foram administrados por iniciativas de cunho privado.

Anterior a essa iniciativa pública, havia poucos registros sobre a atuação do Governo do Estado no litoral gaúcho. Mas, entre as ocorrências encontradas durante a pesquisa de mestrado e doutorado sobre a história do veraneio no Rio Grande do Sul, o projeto de fixação de dunas parece ter sido uma das primeiras formas de intervenção no espaço costeiro, pois nos Relatórios de Obras Públicas do Governo do Estado do Rio Grande do Sul, é possível acompanhar, no decorrer de quinze anos, a ação que se iniciou com caráter experimental em 1919 (RIO GRANDE DO SUL, 1920).

De acordo com o Relatório de obras públicas de 1921, a ação para conter as dunas teria iniciado após a consulta do dunicultor (sic) italiano Miroli, que veio da Argentina para visitar o litoral gaúcho e indicou, na ocasião, o plantio das espécies lomba-verde, cedro marítimo e álamo italiano para florestar o litoral (RIO GRANDE DO SUL, 1922). Segundo o Relatório (1921), o plantio já havia prosperado com maior sucesso na praia de Torres, pois o "vento em Tramandaí havia arrasado tudo, sendo por isso construído uma cerca de tiririca" (RIO GRANDE DO SUL, 1921, p. 157).

Perseverante em seu intento, o diretor J. L. Faria Santos revela que gostaria que o plantio de álamos fosse utilizado para exploração de madeira, a exemplo do que fez a França (RIO GRANDE DO SUL, 1922). Esse fato permite inferir que, além das motivações econômicas que ultrapassavam a intenção de ordenar o espaço litorâneo, o plantio de espécies para a fixação de dunas não se baseava apenas no exemplo do Uruguai e da Argentina, mas também na experiência da França e da Itália.

Tenho a esperança de ver, antes de chegar ao termo da minha existência, o início das florestas que hão de cobrir os cômoros desoladores que bordam as praias do Atlântico em nosso Estado. Além do efeito estético 
e melhoramento do clima, introduziremos novas indústrias, originais da cultura do álamo italiano e pinheiro marítimo. (RIO GRANDE DO SUL, 1921)

Uma década mais tarde, o relatório assinado pelo fiscal Martimiano Leal revela que, após seis anos de trabalho para fixar as areias, a praia de Tramandaí contava com uma área de $30.000 \mathrm{~m}^{2}$ de árvores, demonstrando o quanto o projeto fora perseverante. O fiscal ainda recomendava o plantio das espécies de lomba-verde e eucaliptos, por serem de grande utilidade para a praia de Capão da Canoa, e que a construção de antidunas na praia de Cidreira evitaria a invasão das areias na praia (RIO GRANDE DO SUL, 1930).

Ainda em 1930, foram plantadas 10.800 mudas de lomba-verde na praia de Tramandaí, 1.750 mudas de eucaliptos em Capão da Canoa, além de 2.000 árvores cedidas aos particulares (RIO GRANDE DO SUL, 1930), o que mostra o incentivo público diante dos primeiros processos de transformação dos balneários marítimos. Alguns anos mais tarde, apesar da falta de recursos que limitavam o serviço, o relatório de 1936 enfatizava a iniciativa de "transcendental importância para a zona litorânea" (RIO GRANDE DO SUL, 1936, p. 55).

Se o processo de fixação de dunas atribuía outros sentidos à paisagem e à relação homem-natureza, é interessante notar que, durante a citada visita do Diretor de Higiene às praias, essa ação não foi mencionada como um fator que possibilitava ao homem revisitar aquela natureza "encantada", que tornava a praia acolhedora para seus usos sociais (BERTRAND, 2000). Essa evidência leva a constatar que as medidas preventivas em relação às condições sanitárias nos balneários constituíam um indício das preocupações que emergiam com a modernização e urbanização do litoral.

É nesse encontro entre a política e o urbanismo que os projetos de modernização transformaram as estações balneárias em cidades balneárias. Ainda em 1939, a inauguração da rodovia Gravataí-Osório-Tramandaí, aproximou o litoral da capital dos gaúchos e diminuiu o tempo de viagem até a praia. Essas mudanças em relação às viagens foram recordadas por Nilo Ruschel, que rememora com saudosismo a história das viagens 
ao litoral, afirmando que a proximidade reduziu o encantamento de outrora e, consequentemente, a apreciação da beira-mar.

Apenas duas horas e pouco de passeio por uma estrada lisa, nos separam da faixa comprida de mar, [sic] que debrua, de ponta a ponta, o nosso Estado. Este foi o refúgio presente que o governo entregou à nossa população, no natal de 38 .

E a gente viaja a Tramandahy, mal acreditando na facilidade com que se conquista uma distancia, ontem, quase instransponível. Mas a máquina avança sempre, sem obstáculos, e entrega aos nossos olhos panorama sem fim do Atlântico.

Há alguns anos atrás, repetimos aqui essas cenas batidas dos filmes americanos, mostrando as longas caravanas que se atiravam na conquista do oeste. Si que era ao contrário: fazia-se a marcha para leste, em busca das delicias praieiras. Os automóveis mais velhos que a cidade tinha, eram os veículos escolhidos para o sacrifício dos maus caminhos. Mas não se notava sua velhice, pois ficavam disfarçados sob um montão de malas, de sacos de viagem e de "preguiçosas". Lá se iam nessa aventura que começara ás três horas da madrugada, para terminar ao anoitecer.

Mas Tramandahy aparecia enfim. Seus ranchos de madeira, cobertos de palha, eram uma promessa de repouso, na simplicidade de uma vida quase primitiva.

De manhã cedo, muito antes do sol, os veranistas rumavam a praia, numa longa caravana de carretas, puxadas por quatro ou seis juntas de bois. Carretas de toldos recurvados, feitos com a palha do junco, formando um espetáculo pitoresco, naquela longa marcha móvel, esticando-se entre a brancura dos cômoros de areia. Depois a multidão espalhava-se pela praia e ia adorar o sol nascendo.

Domingo, depois de muitos anos, fui encontrar uma Tramandahy bem diferente. Nada daquela antiga feição primitiva, que era um manto de repouso estendido sobre as areias. Parecia o bairro mais intenso de uma cidade grande. Não encontrei mais velhas carretas, que eram o detalhe mais bonito que o balneário oferecia.

Em seu lugar vi um trilho fazendo uma grande curva dentro da vila e esticando-se entre os cômoros, até a beira do mar. Sobre ele, um carromotor barulhento e enferrujado, pioneiro da mecanização do balneário. As ruas multiplicam-se e por elas, cruzam os automóveis "granfinos" da capital. (grifos do autor)

Hoje, em duas horas apenas, chega-se até á beira mar. Mas não se encontra mais aquela velha Tramandahy com sua longa procissão de carretas entre os cômoros, e com a multidão madrugadora, adorando o nascer do sol na praia. Quanto mais perto, mais longe fica essa Tramandahy. (RUSCHEL, 1939) 
A distância entre Porto Alegre e o litoral ficou, ao longo das décadas, cada vez menor. O processo de urbanização e o aumento populacional nas praias balneárias implicaram em várias mudanças na paisagem litorânea. No entanto, os melhoramentos que atendiam o desejo de beira-mar causavam certo "desencantamento" em relação à utopia inicial que os balneários representavam.

Para Max Weber, a racionalização é responsável pelo desencantamento do mundo (Entzauberung der Welt), principalmente em sua dimensão religiosa (LÖWITH, 1997). Mas a racionalidade atinge outras esferas da vida humana e pode redundar na perda de outros encantos. Como a urbanização dos balneários marítimos foi um efeito da modernização e dos usos do tempo de lazer, pode-se deduzir que a história dos banhos de mar no Rio Grande do Sul se inscreve em uma história de (des)ilusão em relação ao litoral, pois de lugar perigoso e cujas forças da natureza - como correntezas, ventos, tempestades de areia, marés altas - pareciam indomáveis, o litoral se tornou uma paisagem utópica para a formação de sociedades futuras pautadas no discurso científico.

Além do discurso médico, o urbanismo das décadas de 1930 e 1940 também vislumbrou o litoral em seus projetos utópicos. Após vários investimentos e incrementos, o litoral se tornou uma cidade balneária com os padrões de modernidade e isso também significou fazê-lo um lugar de descanso e de divertimento. Para isso, operou-se uma série de mudanças até que fosse possível oferecer aos veranistas aquilo que pode ser considerado o suprassumo da condição moderna, ou seja, viver em conforto. Mas, o conforto, por mais efêmero que seja - dependendo do tempo do veranista, de um final de semana, feriado ou até o veraneio inteiro -, foi possível por um processo de homogeneização, que tornou tudo, mesmo as habitações e o cotidiano nas praias de mar, como algo familiar. Enfim, o estranhamento que se tinha ao rumar para as praias, e do qual deriva, em grande parte, o sentimento de encantamento, foi sendo anulado pela modernização. 


\section{Conclusão}

Ao longo das décadas, a paisagem do litoral perdeu sua magia, desencantou-se. Os sons das rodas das carretas de bois foram sendo substituídos pelos motores dos automóveis que acusavam a chegada dos veranistas. O cheiro dos colchões e demais artefatos de palha, que faziam parte do cotidiano dos veranistas, se dissipou para sempre na brisa marítima. As dunas móveis de areias foram sendo removidas ou fixadas para dar lugar às quadras dos loteamentos e de arruamento geométrico. As árvores exóticas, como os eucaliptos e as acácias, se proliferaram nos balneários. As pequenas aldeias de pescadores foram suprimidas pelo novo desenho urbano dos balneários marítimos, nos quais os hotéis e cassinos surgiam como novas referências à paisagem praieira. A eletrificação das casas, o arruamento dos balneários, os belvederes e avenidas à beiramar "domesticaram" a paisagem das praias de mar. O pitoresco da viagem demorada sobre cômoros de areias, contornando as lagoas, a hospitalidade das pousadas ao longo do caminho, a melodia das músicas que preenchiam as noites sob o céu estrelado, a contemplação do ambiente natural e outros aspectos dos primórdios da vilegiatura marítima foram deixando de fazer parte das novas gerações de veranistas.

O que é interessante perceber na utopia balneária é que os projetos de cidade se desenvolveram a partir da morfologia do lugar e dos elementos culturais que foram incorporados ao espaço marítimo. Junto ao mar, os banhistas assimilaram e adaptaram seus modos de vidas a um novo contexto e território, criando, assim, um sentido comum de vida.

Atualmente, a praia tem sido reinventada pelos novos atores dos balneários do litoral norte do Rio Grande do Sul. Inclusive, os condomínios fechados na orla atlântica, com jardins de plantas exóticas, lagos artificiais, centros comerciais e áreas esportivas, não deixam de sugerir um simulacro pós-moderno dos balneários marítimos de outrora, dando início à história da distopia balneária pela mudança antrópica na paisagem ou pela ocupação desordenada e capitalista do território marítimo. 


\section{Referências}

A GAIVOTA: revista das praias balneárias do Rio Grande do Sul, Rio Grande do Sul, 1929. Acervo: Instituto Histórico e Geográfico do Rio Grande do Sul, Porto Alegre.

A GAIVOTA: revista das praias balneárias do Rio Grande do Sul, Rio Grande do Sul, 1930. Acervo: Instituto Histórico e Geográfico do Rio Grande do Sul, Porto Alegre.

ANDERSON, Benedict. Comunidades imaginadas. São Paulo: Companhia das Letras, 2008.

BERTRAND, Frédéric. As relações Homem-Natureza no quadro dos litorais Atlânticos.

Revista RA'EGA, Curitiba, n. 4, p. 7-21, 2000.

CONDIÇÕES SANITÁRIAS DE NOSSAS PRAIAS. A Gaivota, revista das praias balneárias do Rio Grande do Sul, Rio Grande do Sul, p. 32, 1930.

CORBIN, Alain. Território do vazio: a praia e o imaginário ocidental. São Paulo: Companhia das Letras, 1988.

CHERSO, Francesco Patrizi da. A cidade Feliz. Campinas: Editora UNICAMP, 2011.

DE PORTO ALEGRE ÀS PRAIAS. A Gaivota, revista das praias balneárias do Rio Grande do Sul, Rio Grande do Sul, p. 39, 1929.

ELIAS, Norbert. L’Utopie. Paris: La Découverte, 2014.

ENKE, Rebecca Guimarães. Balneário Villa Sequeira: a invenção de um novo lazer (18901905). 2005. Dissertação (Mestrado em História) - UNISINOS, 2005.

FERREIRA, Felipe Nóbrega. Ao sul do sul o mar também é pampa: sensibilidades de verão na Villa Sequeira, Rio Grande/RS (1884-1892). 2012. Dissertação (Mestrado em História) Universidade Federal do Rio Grande do Sul, Porto Alegre, 2012.

FIRPO, Luigi. Para uma definição da “Utopia”. Revista Morus, Campinas, n. 2, p. 227-237, 2005. Dossiê: Utopia como gênero literário.

FOIGNY, Gabriel de. A terra austral conhecida. Campinas: Editora UNICAMP, 2011.

IGREJINHA CATITA DE NOSSA SENHORA DA SAÚDE, VILLA CRUZ E MAIS ALGUNS CHALETS, DIAS ANTES DO INÍCIO DA TEMPORADA BALNEÁRIA DE 1928-1929. A Gaivota, revista das praias balneárias do Rio Grande do Sul, Rio Grande do Sul, 1929, p.28. 
JORNADA VITORIOSA. A Gaivota, revista das praias balneárias do Rio Grande do Sul, Rio Grande do Sul, 1940.

LAURENCE, Nicolas. Beauduc l'utopie des gratte-plage: ethographie d'une communauté de cabaniers sur le litoral camarguais. Marseille: Monouvreus Editions, 2008.

LÖWITH, Karl. Max Weber e Karl Marx. In: GERTZ, René (org.) Max Weber e Karl Marx. São Paulo: Editora Hucitec, 1997. p. 17-31.

MORUS, Thomas. Utopia. São Paulo: Martins Fontes, 2009.

NONOHAY, Ulysses. As férias. A Gaivota, revista das praias balneárias do Rio Grande do Sul, Rio Grande do Sul, p. 22, 1929.

PINHEIRO, Maria Terezinha Gama. A fundação do balneário Cassino ao final do século XIX e sua expansão e transformação no decorrer do século XX. 1999. Dissertação (Mestrado em Geografia) - Universidade Federal de Santa Catarina, Florianópolis, 1999.

PISTORELLO, Daniela. Comunidade, nação e nacionalismo numa perspectiva cultural. Resenhas Online, São Paulo, ano 10, n. 11103, mar. 2011. Disponível em: http://www.vitruvius.com.br/revistas/read/resenhasonline/10.111/3899. Acesso em: 30 mar. 2021.

RIO GRANDE DO SUL. Relatório apresentado ao Dr. A. A. Borges de Medeiros, Presidente do Estado do Rio Grande do Sul. Engenheiro Ildefonso Soares Pinto, Secretário do Estado dos Negócios das Obras Públicas em 6 de agosto de 1920. Porto Alegre: Memorial do Legislativo do Rio Grande do Sul, 1920.

RIO GRANDE DO SUL. Relatório de Obras Públicas apresentado ao Dr. A. A. Borges de Medeiros, Presidente do Estado do Rio Grande do Sul. Engenheiro Ildefonso Soares Pinto, Secretário do Estado dos Negócios das Obras Públicas em 16 de agosto de 1921. Porto Alegre: Memorial do Legislativo do Rio Grande do Sul, 1921.

RIO GRANDE DO SUL. Relatório de Obras Públicas apresentado ao Dr. A. A. Borges de Medeiros, Presidente do Estado do Rio Grande do Sul. Engenheiro Ildefonso Soares Pinto, Secretário do Estado dos Negócios das Obras Públicas em 15 de agosto de 1922. Porto Alegre: Memorial do Legislativo do Rio Grande do Sul, 1922.

RIO GRANDE DO SUL. Relatório apresentado ao Exmo. Sr. Dr. Getúlio Vargas- Presidente do Estado do Rio Grande do Sul pelo Engenheiro Civil J. Fernandes Moreira- Secretário de Estado dos Negócios das Obras Públicas em julho de 1930. Porto Alegre: Oficinas Graphicas da Federação, 1930. v. 2. 
RIO GRANDE DO SUL. Relatório do Estado do Rio Grande do Sul. Mensagem enviada à Assembleia Legislativa pelo Dr. Darcy Azambuja- Secretário dos Negócios do Interior, no exercício do cargo de Governador do Estado, em $1^{\circ}$ de Junho de 1936 . Porto Alegre: Imprensa Oficial, 1936.

ROULLIARD, Dominique. La site balnéaire. Paris: Pierre Mardaga éditeur, 1984.

RUSCHEL, NILO. ATLANTICO. A Gaivota, revista das praias balneárias do Rio Grande do Sul, Rio Grande do Sul, 1939.

SARGENT, Lyman Tower. Traditions utopiques: thèmes et varations. In: SCHAERER, Roland; SARGENT, Lyman Tower (dir.). Utopie: la quête de la société idéale en Occident. Paris: Bibliothèque Nationale de France: Fayard, 2000.

SCHOSSLER, Joana C. História do veraneio no Rio Grande do Sul. Jundiaí: Paco Editorial, 2013.

SCHOSSLER, JOANA C. Utopias marítimas no Atlântico Sul: imaginário e tipologias no litoral do Uruguai e do Rio Grande do Sul (1860-1950). 2016. Tese (Doutorado em História) - Universidade Estadual de Campinas, Campinas, 2016.

SCHOSSLER, Joana C.; TOULIER, Bernard. L'influence du modèle européen sur les stations balnéaires d'Amérique du Sud: I'exemple du Brésil méridional et de l'Uruguay.

Revista Mondes du Tourisme [En ligne], n. 17, 01 juin. 2020. Disponível em: http://journals.openedition.org/tourisme/2763. Acesso em: 13 abr. 2021.

SILVA, Manoel d'Azevedo. Banhos de mar nas costas do Brazil. Rio de Janeiro: [s.n.], 1893.

TOULIER, Bernard. Les réseaux de la villégiature en France. In Situ [En ligne], Paris, n. 4, 01 mars 2004. Disponível em: http://insitu.revues.org/1348. Acesso em: 14 fev. 2014.

TOURAINE, Alain. La societé comme utopie. In: SCHAERER, Roland; SARGENT, Lyman Tower (dir.). Utopie: la quête de la société idéale en Occident. Paris: Bibliothèque Nationale de France, Fayard, 2000.

URBAIN, Jean-Didier. Sur la Plage: moeurs et coutumes balnéaires, XIX-XX siècles. Paris: Petite Bibliothèque Payot, 2007. 
Recebido em: 14/07/2020 Aprovado em: 24/04/2021

Universidade do Estado de Santa Catarina - UDESC Centro de Ciências Humanas e da Educação - FAED

PerCursos

Volume 22 - Número 48 - Ano 2021 revistapercursos@gmail.com 